\title{
Network Interconnection with Participation Constraints
}

\author{
Stephen Poletti ${ }^{\mathrm{a}, *}$,Julian Wright ${ }^{\mathrm{b}}$ \\ ${ }^{a}$ Department of Economics, University of Auckland, Private Bag 92019, Auckland, \\ New Zealand \\ ${ }^{\mathrm{b}}$ Department of Economics, National University of Singapore, AS2 Level 6, 1 Arts \\ Link, Singapore 117570
}

\begin{abstract}
This paper builds on the existing literature on telecommunications interconnection with non-linear pricing and heterogeneous agents, by explicitly taking into account consumers' participation decision. This single change leads to dramatically different conclusions regarding the scope for collusion by interconnecting networks.
\end{abstract}

Key words: Access Pricing; Telecommunications; Regulation

JEL Classification: L50, L96

\section{Introduction}

One of the key issues facing regulators in the telecommunications sector is that of interconnection. In most cases, the opportunity for entrants to interconnect with the incumbent network under reasonable terms and conditions is essential to ensure effective competition in telecommunication networks. As Laffont et al. (1998, p7) observe, "Interconnection, however, requires cooperation among competitors, who must agree on its mode and especially its price." Thus, the need for interconnection raises concern about anti-competitive behavior. At worst the terms of interconnection can be used to blockade entry, while if entry does occur there is concern that the firms can use the negotiated access price as a strategic variable, allowing the firms to effectively collude in setting retail prices (see for instance Armstrong, 1998, Laffont et al., 1998 and Carter and

* Corresponding Author

Email address: s.poletti@auckland.ac.nz (Stephen Poletti). 
Wright, 1999). These anti-competitive effects of interconnection are derived assuming firms compete in linear retail prices.

The case for deregulation is much stronger once firms are allowed to compete in non-linear retail prices (as they are known to do). Provided the networks are restricted to charge each other reciprocal per-minute access charges, Laffont et al. (1998) show that the firms cannot use access charges to increase profits. With non-linear retail pricing, firms charge for usage at perceived marginal cost and extract profit by setting line rentals above cost. Any increase in a reciprocal access price above cost will increase usage charges but result in greater competition for subscribers to attract the above cost access revenues. This suggests that once interconnection and reciprocal charging arrangements are established, there may be no need to directly regulate access fees. Given the significance of this conclusion for policy, it is important to ask whether these results still hold for more realistic models?

Taking up this challenge, Dessein (1999a, 1999b, 2003) explores the robustness of these conclusions by considering what happens in the Laffont et al. (1998) framework once there is heterogeneity in customers' demand. ${ }^{1}$ He allows for two types of customers, and considers two-part as well as optimal non-linear retail pricing. Even with unbalanced calling patterns, he shows that in most cases there is no scope for collusion; the profits of firms do not depend on the reciprocal access charge they agree on. While firms can set access charges to discourage competition in one sector (resulting in higher tariffs), they do so only at the expense of increased competition and lower tariffs in the other sector. The two effects generally cancel out leaving profit independent of the access charge. ${ }^{2}$

In this paper, we take Dessein's benchmark model of customer heterogeneity and modify it by allowing customers' participation constraint to be binding in equilibrium. We show that this modification leads to dramatically different results. Most importantly, firms are able to achieve a collusive outcome through the setting of reciprocal access charges above cost. ${ }^{3}$

1 Hahn (2000) also examines the effects of heterogeneity on the profit neutrality result of Laffont et. al.(1998). He presents a model with a continuum of different users and reaches similar conclusions to Dessein. De Bijl and Peitz (2002, chapter 7) analyze a model with third-degree price discrimination and two-part tariffs. They find that in a mature market, profits are independent of reciprocal access charges, although consumer surplus and social welfare are maximized by setting access charges to cost.

2 Armstrong (2002) shows this profit neutrality extends to certain models which allow for call externalities.

3 Valletti and Cambini (2002) find a similar result in a model with non-linear retail pricing in which in the first stage the networks make an investment decision, prior to price competition. 
Some other recent papers have shown that reciprocal access charges are no longer neutral even under non-linear pricing. However, these show that cooperation between carriers over reciprocal access charges will result in access prices being set at, or below, cost. For instance, Gans and King (2001) allow for network based price discrimination by firms that use two-part pricing. They find that both networks will strictly prefer access charges set below cost. Schiff (2002) finds that either cost-based (or below-cost) access prices are privately optimal in a model in which firms set two-part pricing and only some customers choose to subscribe to the network, while Dessein (2003) finds that firms will set access prices below cost under a somewhat different partial participation framework. Carter and Wright (2003) model the setting of reciprocal access prices by asymmetric firms that use two-part pricing. They find that both firms will strictly prefer marginal cost access charges when there is a sufficient degree of asymmetry between the two networks. ${ }^{4}$

In Dessein's model of customer heterogeneity with non-linear pricing, the low demand customers' participation constraint is assumed not to be binding in equilibrium. While this is probably a reasonable assumption when consumers are homogeneous, it seems at odds with extensive heterogeneity. More critically, it is inconsistent with the firms using high access charges to increase prices, since these high prices may lead to the participation constraint becoming binding for low demand users. Rather than imposing that customers will always want to participate in the network, in this paper we explicitly allow for the participation constraint. With this modification, we identify two distinct ways that access charges will impact on the firms' profits.

If the participation constraint is binding, then it is the participation constraint rather than competitive pressures which determine tariffs for low demand customers. If the incentive constraint is not binding, an increase in competition has no impact on the package offered to low demand customers. In contrast, for high demand users, it is the degree of competition which determines their tariff menu. If there is a call imbalance between the two sectors, firms can set the access charge so that high demand customers generate an access revenue deficit. The effect of this is to limit competition for high demand customers and increase competition for light users. Although competitive pressure will increase in the light users sector, as long as the participation constraint is binding, tariffs for low demand customers are not affected by the amount of competition. The result is higher tariffs for high demand customers without an offsetting fall in tariffs for low demand customers. Firms will obtain higher profits as a result. We show that this call imbalance effect continues to be

\footnotetext{
4 Armstrong (2002) provides an in-depth survey of these and other cases. See also De Bijl and Peitz (2002) for a numerical analysis of a wide range of interesting scenarios, including cases where the carriers do not set reciprocal access prices and where the process of entry is taken seriously.
} 
important if the incentive constraint is binding.

Firms have another channel for increasing profits, which operates if both constraints are binding. With both the participation and incentive constraints binding, the full non-linear tariffs for both high and low demand users are completely determined by the usage fees. The tariff for light users is the available consumer surplus which is a direct function of the quantity offered. For the high demand customers, once the usage fee is set, the tariff is then determined by the incentive constraint. With both constraints binding, the situation is analogous to competition in the linear price regime, where the access charge directly influences the usage fee and hence the tariff. Although firms here can use the relationship between usage price and the tariffs to increase profits, they cannot restore monopoly profit. The reason is that firms cannot use the access charge to influence the usage fee for high and low demand users separately. As before, the arena of competition is the high demand sector. An increase in competition means that firms offer lower fixed fees to attract high demand customers. The usage fee for light users is then determined by the constraints. Firms can use the access charge to turn this relationship on its head. A high access charge can be used to ensure a high usage fee for light users. This, in turn, forces firms via the incentive constraint to charge higher fixed fees for heavy users. There is a trade-off, however. The access charge also determines the usage fee for high demand users. As a result, firms offer these users a sub-optimal number of call minutes. Thus, monopoly profits are not completely restored. Unlike the "call imbalance" effect discussed in the previous paragraph, this mechanism operates even if calling patterns are balanced.

If customers are homogenous, we find that firms cannot use above-cost access charges to increase profits, even if the participation constraint is binding - in fact the optimum access charge is at cost. If customers are heterogenous, the introduction of the participation constraint leads to results that are more like those under linear retail pricing. If competition is light, firms choose to set usage fees above cost to both low and high demand customers. They achieve these prices by agreeing on above-cost reciprocal access charges. Moreover, up to a point, the greater the degree of competition, the more they will increase the reciprocal access charge above cost. As competition increases further, the "call imbalance channel" becomes significant and can result in firms setting access charges that are either positive or negative depending on the net inflow of calls into the heavy users sector. We find that with imbalances in traffic, firms can increase profits significantly. However, consumer surplus is substantially reduced as a consequence. Thus, we conclude that to the extent the assumptions underlying our model apply, privately negotiated access charge arrangements can lead to undesirable outcomes - at least from a social perspective. 
The rest of the paper proceeds as follows. Section 2 introduces Dessein's model of heterogenous consumers and network competition. Section 3 introduces the participation constraint and derives the equilibrium for the cases in which the participation and incentive constraints are binding, as well as when they are not binding. In Section 4, we present numerical solutions to illustrate our results. Some conclusions are drawn in Section 5.

\section{Dessein's model}

To model network competition with heterogenous consumers, we adopt Dessein's (1999a, 1999b, 2003) approach. There are two full coverage networks which have the same cost structure. Each network incurs a cost $c_{0}$ per minute to originate and terminate a call with a marginal cost of $c_{1}$ per minute in between. Thus, the total marginal cost of a call is

$$
c=2 c_{0}+c_{1} \text {. }
$$

It is assumed that there are two types of customers, high demand customers who gain variable gross surplus $V_{H}\left(q_{H}\right)$ from consuming $q_{H}$ minutes of phone services and low demand customers who gain gross surplus $V_{L}\left(q_{L}\right)$ for calls of $q_{L}$ minutes. The standard Hotelling model is used to differentiate the networks. Customers are located on a unit interval with the networks located at the two extremes. Given income $y$ and telephone consumption $q_{S}$, a consumer of type $S$ joining network $i$ has utility

$$
y+V_{S}\left(q_{S}\right)+v_{0}-\tau\left|x-x_{i}\right| .
$$

The term $v_{0}-\tau\left|x-x_{i}\right|$ represents the additional benefits a customer located at $x$ receives from belonging to the network located at $x_{i}$. Each firm faces per customer costs $f$, as well as marginal costs of $c$ per minute of calling. The fraction of consumers who are light users is $\mu$, while $(1-\mu)$ are heavy users. The representative firm has market share $\alpha_{S}$ and charges tariffs $t_{S}$ in sector $S$, while the rival firm offers a package of $q_{S}^{\prime}$ minutes at a tariff of $t_{S}^{\prime}$ and has market share $\alpha_{S}^{\prime}=1-\alpha_{S}$. The distribution of $x$ is assumed to be uniform on the unit interval, independent of whether customers are high or low demand customers. With heterogenous customers it is natural to assume that calling patterns depend on the type of user. Using notation introduced by Dessein (2003), a fraction $l$ of all calls terminate on the light user segment, where $l$ is independent of the type of customer who initiates the call.

The variable net surplus that each customer of type $S$ obtains from a tariff package of $q_{S}$ calling minutes offered at a tariff $t_{S}$ is $u_{S}\left(q_{S}, t_{S}\right)=V_{S}\left(q_{S}\right)-t_{S}$. The market share of each firm is then determined from the requirement that 
a customer located at $x=\alpha$ be indifferent to the packages offered by the rival firms which yields the market share equation

$$
\alpha_{S}=\frac{1}{2}+\gamma\left[u_{S}\left(q_{S}, t_{S}\right)-u_{S}\left(q_{S}^{\prime}, t_{S}^{\prime}\right)\right]
$$

for $\gamma=1 / 2 \tau$. The parameter $\gamma$ captures the degree of competition in the market. Perfect competition is approximated by the limit $\gamma \longrightarrow \infty$ with the monopoly limit being $\gamma=0$.

Firms can gain reciprocal access rights to each others networks at a unit access charge of $a$. It is assumed here that each firm faces the same access charge which is a charge for call termination on the rival network. The expected profit for the representative firm offering $q_{S}$ units at tariff $t_{S}$ in each sector is given by

$$
\begin{gathered}
\pi=\mu \alpha_{L}\left[t_{L}-c q_{L}-f\right]+(1-\mu) \alpha_{H}\left[t_{H}-c q_{H}-f\right] \\
-\left[\mu \alpha_{L} q_{L}+(1-\mu) \alpha_{H} q_{H}\right]\left[l\left(1-\alpha_{L}\right)+(1-l)\left(1-\alpha_{H}\right)\right]\left(a-c_{0}\right) \\
+\left[\mu\left(1-\alpha_{L}\right) q_{L}^{\prime}+(1-\mu)\left(1-\alpha_{H}\right) q_{H}^{\prime}\right]\left[l \alpha_{L}+(1-l) \alpha_{H}\right]\left(a-c_{0}\right) .
\end{gathered}
$$

The first line represents retail profit that the representative firm would make if all calls terminated on their own network. The last two lines represent the net access revenue (or deficit) on calls which cross networks. If heavy users only called heavy users, then the access revenues on the heavy user sector would be

$$
(1-\mu) \alpha_{H} \alpha_{H}^{\prime}\left(a-c_{0}\right)\left[q_{H}^{\prime}-q_{H}\right] .
$$

If, however, a fraction $l$ of calls terminate on the light users segment, then the access deficit (or surplus) due to heavy users is

$$
A_{H}=(1-l)(1-\mu) \alpha_{H} \alpha_{H}^{\prime}\left(a-c_{0}\right)\left[q_{H}^{\prime}-q_{H}\right]+l(1-\mu) \alpha_{H} \alpha_{L}^{\prime}\left(a-c_{0}\right)\left[q_{L}^{\prime}-q_{H}\right] .
$$

Similarly, the access deficit (or surplus) due to light users is

$$
A_{L}=l \mu \alpha_{L} \alpha_{L}^{\prime}\left(a-c_{0}\right)\left[q_{L}^{\prime}-q_{L}\right]+(1-l) \mu \alpha_{L} \alpha_{H}^{\prime}\left(a-c_{0}\right)\left[q_{H}^{\prime}-q_{L}\right] .
$$

Combining the access terms with the retail profit term results in the expression in (2). Each firm is assumed to set its retail tariff structure to maximize profits.

So far we have not made any assumption about the demand function. Laffont et al. (1998) and Dessein (1999a, 1999b, 2003) assume a constant elasticity demand function, while Armstrong (1998), and Carter and Wright (1999) use a linear demand function. The analysis presented here simplifies somewhat for a linear demand function, which we will make use of at times. This corresponds to the net surplus function

$$
V_{S}\left(q_{S}\right)=\left(k_{S}-b q_{S}\right) q_{S}
$$

High demand users are characterized by high values of the parameter $k$. 


\section{Equilibrium with a participation constraint}

Dessein (1999a, 1999b, 2003) found that incorporating heterogeneity in consumer types did not effect the standard "neutrality" result with non-linear pricing - profits are independent of the reciprocal access charge. However, in doing so, the participation constraint was ignored. ${ }^{5}$ In contrast, we allow for an explicit participation constraint. The aim is to see if the equilibrium profits for the firms depend on the access charges. Although the solutions can be written in closed form, the expressions are somewhat complicated. Where necessary we use special cases or approximations to interpret the equilibrium conditions.

\subsection{Introducing a participation constraint}

The problem faced by a monopoly provider of the phone network is to extract the maximum possible consumer surplus. With non-linear tariffs, the monopolist will set the marginal usage fee equal to marginal cost and use the "fixed" part of the tariff to extract consumer surplus. The monopoly firm is faced with a problem - if the "fixed" fee is set too high, customers will choose not to join the network. Thus, in a market dominated by a monopoly carrier, it is the participation constraint that determines the overall profit rate. Similarly, if there is limited competition, then the participation constraint will continue to limit firm profits.

In practice, firms' ability to extract consumer surplus is also limited because they are unable to practice perfect price discrimination. Here, we adopt Dessein's assumption that only second-degree price discrimination is possible. With second-degree price discrimination, the willingness of customers to participate puts natural limits on the retail tariff structure that can be set. Firms have to make sure that the tariff bundles they offer are incentive compatible and each type of customer will freely choose the bundle designed for them. The participation constraint for our model is given by

$$
u_{L}=V_{L}\left(q_{L}\right)-t_{L} \geq 0
$$

The participation decision for low demand customers is assumed to be independent of customers' location (draw of $x$ on the unit interval). If transportation costs are considered a real cost for customers, then a literal interpretation of the Hotelling model would imply a participation constraint that depends on customers' position $x$. Such an interpretation of the Hotelling model leads

\footnotetext{
5 Dessein (2003) does consider partial participation in the context of a model with a continuum of consumers with homogenous volume demand.
} 
to results which are awkward to work with. Instead, we favor an alternative interpretation presented in Appendix A which leads to the simple participation constraint given in equation (4), while maintaining the Hotelling market shares, as in Dessein's model in Section 2.

Firms will design a tariff bundle so that high demand customers do not wish to consume the low demand customers' bundle. The incentive constraint is written as

$$
u_{H}=V_{H}\left(q_{H}\right)-t_{H} \geq V_{H}\left(q_{L}\right)-t_{L} .
$$

It can easily be checked that if the incentive constraint is binding, low demand customers strictly prefer the package designed for them. However, if the incentive constraint for high demand customers fails to bind, then it is important to check that the incentive constraint for the light users is satisfied. ${ }^{6}$

We will also impose that the firms wish to service both types of customers, which will be the case provided customers are not too heterogenous. If customers are sufficiently heterogenous, it may make sense for the firms to exclude low demand customers completely from the market in order to relax the incentive constraint and extract more profit from the high demand users. Under most regulatory regimes, fixed line telecommunication carriers have a statutory obligation to service all low demand users for a 'reasonable price'. Our results will thus be more directly applicable to fixed line telecommunication service than to mobile networks, where coverage is only partial because tariff packages fail to meet the participation constraint of a significant part of the market. ${ }^{7}$

Each firm maximizes profits subject to the two types of constraints - which means solving the first order conditions of the Lagrangian

$$
\pi\left(q_{L}, t_{L} ; q_{L}^{\prime}, t_{L}^{\prime}\right)+\lambda_{1}\left(u_{L}\right)+\lambda_{2}\left(u_{H}-u_{L}+V_{L}\left(q_{L}\right)-V_{H}\left(q_{L}\right)\right),
$$

where $\pi\left(q_{L}, t_{L} ; q_{L}^{\prime}, t_{L}^{\prime}\right)$ is given by equation (2). The standard strategy in the literature is to write the profit function in terms of $u_{S}$ and $q_{S}$ instead of $t_{S}$ and $q_{S}$. This is the approach taken here. After deriving the first order conditions, symmetric equilibrium conditions are imposed. This yields the constraint equation, if $\lambda_{1}>0$, of

$$
u_{L}\left(q_{L}\right)=0 \Longleftrightarrow V_{L}\left(q_{L}\right)=t_{L},
$$

and for $\lambda_{2}>0$, of

$$
\begin{gathered}
u_{H}-u_{L}+V_{L}\left(q_{L}\right)-V_{H}\left(q_{L}\right)=0 \\
\Longleftrightarrow t_{H}=V_{H}\left(q_{H}\right)-V_{H}\left(q_{L}\right)+V_{L}\left(q_{L}\right) .
\end{gathered}
$$

\footnotetext{
$\overline{6}$ In the numerical examples presented in Section 4 this is checked explicitly.

7 Dessein (2003) and Schiff (2002) consider models of interconnection with partial participation, while Wright (2002) considers the case of mobile networks specifically.
} 
Taking derivatives of (6) with respect to $u_{L}, u_{H}, q_{L}$, and $q_{H}$ gives the system of equations

$$
\begin{gathered}
\mu \gamma\left[t_{L}-c q_{L}-f\right]+2 \mu \gamma\left(a-c_{0}\right) \underline{A}_{L}=-\lambda_{1}+\lambda_{2}+\mu / 2, \\
(1-\mu) \gamma\left[t_{H}-c q_{H}-f\right]+2(1-\mu) \gamma\left(a-c_{0}\right) \underline{A}_{H}=-\lambda_{2}+(1-\mu) / 2, \\
\frac{\mu}{2}\left[V_{L}^{\prime}\left(q_{L}\right)-\left(c+\frac{\left(a-c_{0}\right)}{2}\right)\right]=-\lambda_{2}\left[V_{L}^{\prime}\left(q_{L}\right)-V_{H}^{\prime}\left(q_{L}\right)\right],
\end{gathered}
$$

and

$$
p_{H}=V_{H}^{\prime}\left(q_{H}\right)=c+\frac{\left(a-c_{0}\right)}{2},
$$

where the call imbalance per light and heavy user users is denoted by

$$
\begin{aligned}
\underline{A}_{L} & =\frac{1}{2 \mu}\left[l(1-\mu) q_{H}-\mu(1-l) q_{L}\right], \\
\underline{A}_{H} & =\frac{1}{2(1-\mu)}\left[\mu(1-l) q_{L}-l(1-\mu) q_{H}\right] .
\end{aligned}
$$

Note that the total call imbalance is zero, so $\mu \underline{A}_{L}+(1-\mu) \underline{A}_{H}=0$.

For a symmetric equilibrium with $\alpha_{S}=\alpha_{S}^{\prime}=1 / 2$ the total profits per firm are

$$
\frac{\mu}{2}\left[t_{L}-c q_{L}-f\right]+\frac{(1-\mu)}{2}\left[t_{H}-c q_{H}-f\right]=\frac{1-2 \lambda_{1}}{4 \gamma} .
$$

If the participation constraint is binding, then $\lambda_{1}>0$ and profits are lower. The fact that firms have to worry about the incentive constraint also impacts on profits, but only indirectly. Without the participation constraint $\left(\lambda_{1}=0\right)$, the profit per firm is $1 / 4 \gamma$, which is clearly independent of the negotiated access charge, a result obtained by Dessein. If demand is linear, the usage fee for light users can be found in terms of the Lagrange multiplier

$$
p_{L}=V^{\prime}\left(q_{L}\right)=\left[c+\left(a-c_{0}\right) / 2\right]+\frac{2 \lambda_{2} \bar{k}}{\mu},
$$

where $\bar{k}=k_{H}-k_{L}$. Thus, to satisfy the incentive constraint, the usage fee for the low demand customers is increased.

The behavior of the solution to the system of equations presented here depends on whether or not the constraints are binding. The different possibilities are analyzed below. We first consider the case with a binding participation constraint, but not a binding incentive constraint. We then turn to the case where both constraints are binding. 


\subsection{Binding participation constraint only}

To get some insight into how the participation constraint affects the behavior of the firms, we start by looking at some simple examples. The simplest possible case is one with a single type of customer and no participation constraint. This setup was originally analyzed by Laffont et al. (1998) who find that profits are independent of the access charge. The solution without a binding participation constraint (or incentive constraint) can be obtained from the equations $^{8}$ in the previous section by setting $\lambda_{1}=\lambda_{2}=0$. The equilibrium usage fee ${ }^{9}$ is set at perceived marginal cost

$$
p=c+\frac{\left(a-c_{0}\right)}{2} \text {. }
$$

The equilibrium non-linear tariff is given by

$$
t=c q+f+\frac{1}{2 \gamma}
$$

which could be implemented with the two part tariff $t=F+p q$ with $F=$ $f+\gamma / 2-\left[\left(a-c_{0}\right) / 2\right] q$. The non-linear tariff consists of the Hotelling mark-up over costs. It does not depend on the access charge, which is the basis of the result of Laffont, et al. (1998) - firms cannot use the access charge to lessen the intensity of competition.

We first consider how this result is changed by the introduction of a binding participation constraint (before allowing for heterogenous customers).

\subsubsection{Homogeneous customers}

If there is only one type of user and the participation constraint is binding, the firms will still set their usage fee based on their perceived marginal cost, namely $p=c+\left(a-c_{0}\right) / 2$. However, the equilibrium tariff is now equal to the total consumer surplus

$$
t=V(q)
$$

The total profit per firm in equilibrium becomes:

$$
\pi=\frac{1}{2}(V(q)-c q-f),
$$

which is no longer independent of the access charge since $q$ is a function of the access charge. ${ }^{10}$ Taking the derivative of the profit function with respect

\footnotetext{
8 The parameters $\mu$ and $l$ are set so that there is only one sector. For example $\mu=1$ and $l=1$.

9 The usage fee $p$ is defined by $V^{\prime}(q)=p$.

${ }^{10}$ For the linear demand function used here, $q=\left(2 k-\left(2 c+a-c_{0}\right)\right) / 4 b$.
} 
to the access charge gives

$$
\frac{d \pi}{d a}=\frac{1}{2}\left(\frac{\partial V}{\partial q}-c\right) \frac{\partial q}{\partial a}=\frac{a-c_{0}}{4} \frac{\partial q}{\partial a},
$$

which equals zero for $a=c_{0} .{ }^{11}$ Hence, although the firms' profits do depend on the access charge, the best that firms can do is to negotiate an access charge at marginal cost. The reason is straightforward. The fact that the participation constraint is binding means that there is upward pressure on the tariff - in the absence of the participation constraint, firms would set a higher tariff. It is the participation constraint rather than competition which determines the tariff bundle. ${ }^{12}$ The best firms can do in this scenario is to set the usage fee at the true marginal cost and extract the available surplus by charging as high a fixed fee as is consistent with the participation constraint. From a policy perspective, this is a strong result. Firms have a clear incentive to negotiate an access charge arrangement which is socially efficient.

\subsubsection{Heterogeneous customers}

With heterogeneous customers, a new element which emerges is the call imbalance between the heavy and light sectors. This can be seen clearly by first considering the case in which the participation constraint and the incentive constraint is not binding. Suppose firms can explicitly discriminate between the two types of customers so that customers are forced to use the tariff designed for them (that is, we can ignore the incentive constraints that would normally apply). Setting the Lagrange multipliers $\lambda_{1}$ and $\lambda_{2}$ to zero in equations (9) -(12) shows that in the equilibrium, firms set the usage fee for both the high and low users at their perceived average marginal cost $p_{L}=p_{H}=c+\left(a-c_{0}\right) / 2$. The retail profit per light user and heavy user now depend explicitly on the call imbalance:

$$
\left(t_{L}-c q_{L}-f\right)=\frac{1}{2 \gamma}-2\left(a-c_{0}\right) \underline{A}_{L}
$$

and

$$
\left(t_{H}-c q_{H}-f\right)=\frac{1}{2 \gamma}-2\left(a-c_{0}\right) \underline{A}_{H} .
$$

The firms will adjust their tariffs to take into account the net inflow or outflow of calls for each sector. For example, if the access charge is set above cost, a positive call imbalance into the heavy sector implies increased competition for the extra access revenue. This impacts negatively on profits from heavy users. Note that the total net call imbalance $\mu \underline{A}_{L}+(1-\mu) \underline{A}_{H}$ has to sum to zero so

\footnotetext{
${ }^{11}$ For the linear demand function, $\partial^{2} \pi / \partial a^{2}<0$ and so $a=c_{0}$ is indeed a (local) maximum.

${ }^{12}$ Of course, for high enough levels of competition the participation constraint will be relaxed.
} 
the total profit per firm is independent of the access charge and equals $1 / 4 \gamma$ consistent with Dessein.

What happens when there is an explicit participation constraint which binds for the light users? Are profits still independent of the access charge? With homogenous users we saw that the participation constraint limited the impact of competition since it is the participation constraint and not competition which binds for light users. This suggests a possible strategy for the firms, namely to use the access charge and the call imbalance to limit competition for the heavy sector users. Although this means that competition will be stronger in the light users sector, as long as the participation constraint is binding, an increase in competition may have no effect on tariffs in the light users sector. As we show below, if $\underline{A}_{H}>0$, firms wish to set access charges below cost, while for $\underline{A}_{H}<0$, the access charge should be set above cost.

The equilibrium tariffs and usage fees can be found easily by substituting $\lambda_{2}=0$ in the first order equations derived in Section 3.1. Usage fees are set at perceived marginal cost

$$
p_{L}=p_{H}=c+\frac{\left(a-c_{0}\right)}{2} .
$$

The tariff for the heavy users is unchanged by the introduction of the participation constraint. We assume that the participation constraint is not binding for heavy users, so that

$$
\left(t_{H}-c q_{H}-f\right)=\frac{1}{2 \gamma}-2\left(a-c_{0}\right) \underline{A}_{H} .
$$

The access revenue (or loss) resulting from each heavy user is treated as a fixed cost. Thus, if a customer switches networks, the firm would lose $\left(t_{H}-c q_{H}-f\right)$ in direct profit but would pay $\left(a-c_{0}\right) \underline{A}_{H}$ less access revenue and instead would receive extra access revenue of $\left(a-c_{0}\right) \underline{A}_{H}$. The total loss of profit per heavy user is $1 / 2 \gamma$. The tariff for light users is determined by the participation constraint

$$
t_{L}=V_{L}\left(q_{L}\right) .
$$

So long as the participation constraint is binding, the access revenue for light users is no longer treated as a fixed cost. Industry profits are now

$$
\pi=\frac{-\lambda_{1}}{\gamma}+\frac{1}{2 \gamma}
$$

Note that the usage fee offered to both heavy and light users, and the overall tariff offered to light users, is independent of $\gamma$ (the extent of competition). An increase in competition means that firms will compete vigorously over the high demand customers by offering them lower "fixed fees." The participation 
constraint, however, limits the impact of competition over the fixed fee for the light users.

The total profit per firm can be written (after substituting for $q_{L}$ and $q_{H}$ ) as

$$
\begin{aligned}
\pi & =\frac{\mu}{2}\left[V_{L}\left(q_{L}\right)-c q_{L}-f\right]+\frac{(1-\mu)}{2}\left[t_{H}-c q_{H}-f\right] \\
& =\frac{\mu}{2}\left[V_{L}\left(q_{L}\right)-c q_{L}-f\right]+\frac{(1-\mu)}{4 \gamma}-(1-\mu)\left(a-c_{0}\right) \underline{A}_{H} .
\end{aligned}
$$

Firms can use the call imbalance generated by heavy users to directly influence profits. To find out the joint profit maximizing access charge, we take the derivative of $\pi$ with respect to $a$, to get

$$
\frac{\partial \pi}{\partial a}=\frac{\mu}{4}\left(a-c_{0}\right) \frac{\partial q_{L}}{\partial a}-(1-\mu) \underline{A}_{H}\left(q_{L}, q_{H}\right)-(1-\mu)\left(a-c_{0}\right) \frac{\partial \underline{A}_{H}\left(q_{L}, q_{H}\right)}{\partial a} .
$$

Note that at $a=c_{0}$, the expression reduces to

$$
\frac{\partial \pi}{\partial a}=-(1-\mu) \underline{A}_{H}\left(q_{L}, q_{H}\right)=\mu \underline{A}_{L} .
$$

If $\underline{A}_{H}<0$, the profit function increases initially as the negotiated access charge increases from $a=c_{0}$. The converse is also true. For the linear demand function defined by equation (3), the profit maximizing value of $a$ can be calculated explicitly by setting equation (25) to zero, which implies

$$
a-c_{0}=\frac{-16 b(1-\mu)}{4 l-3 \mu} \underline{A}_{H}\left(\bar{q}_{L}, \bar{q}_{H}\right),
$$

with $\bar{q}_{S}$ defined as the quantity offered at $a=c_{0}$. By choosing the access charge so that extra high demand customer carry an access revenue loss, firms can ensure that they have an incentive to set high tariffs for heavy users. The participation constraint is binding for light users so the tariff for light users is independent of their call imbalance - it is completely determined by their usage fee. Since net access revenue in equilibrium is zero, overall profits can be increased by choosing an appropriate access charge.

So far, we have implicitly assumed that the participation constraint is binding for all values of the access charge $a$. As suggested above, as the access charge moves away from $c_{0}$, firms may wish to relax the participation constraint even if it is binding at $a=c_{0}$. The solution space will have regions which are solutions with none, one or both of the constraints binding, and as the access charge changes, different regions of the solution space are covered. We turn now to considering the more complex solution for the case in which both of the constraints are binding. 


\subsection{Binding participation and incentive constraints}

It was argued in the preceding section that if the participation constraint is binding, and the firms are able to price discriminate explicitly, then firms can collude by negotiating an access price either above or below cost (depending on the direction of the imbalance in calls between heavy and light users). In this section, we address whether collusion is still possible if the incentive constraint is also binding. We would expect this to be the case on general grounds. The reason why linear pricing leads to collusive results is that firms have only one instrument to achieve two goals; that of increasing the profit per customer and that of increasing market share. Increasing the access charge limits the ability of firms to compete directly on prices, leading to higher prices and profits. Introducing nonlinear pricing means that the large profits generated by high usage prices are competed away through lower fixed fees. Making the participation constraint binding for low demand consumers means that firms set an access charge that restrains competition for heavy users, with competition for light users not being a binding constraint. As a result, profits increase. Adding another constraint (the incentive constraint) should limit competition further, meaning that the firms should still be able to use the access charge as a strategic variable in the way described above.

With linear demand, and binding incentive and participation constraints, Appendix $\mathrm{B}$ shows that the usage fee offered to light users can be written as

$$
p_{L}=c+\frac{(1-\mu)}{\mu} \bar{k}+\Delta p_{L}
$$

where $\bar{k} \equiv k_{H}-k_{L}$, and $\Delta p_{L}$ depends on the access charge,

$$
\Delta p_{L}=\frac{\left(a-c_{0}\right)}{2}-\gamma \frac{2 \bar{k}(1-\mu)}{\mu} R_{H}\left(q_{H}, q_{L}\right)
$$

with

$$
R_{H}\left(q_{H}, q_{L}\right)=\left[\left(V_{H}\left(q_{H}\right)-\bar{k} q_{L}-c q_{H}-f\right)+2\left(a-c_{0}\right) \underline{A}_{H}\left(q_{H}, q_{L}\right)\right] .
$$

Note that a tariff cut of $\varepsilon$ to the heavy users leads to a direct increase in revenue $^{13}$ of $\gamma \varepsilon R_{H}$ (there will also be an indirect effect due to the loss of revenue from existing customers). The change in the usage fee as the access charge changes is the sum of two terms. The first is the familiar raise each other's cost effect. Perceived marginal costs have changed, increasing the usage charge for light users. The second term will also change as the access charge

\footnotetext{
${ }^{13}$ An extra customer results in an increase in access charges of $2\left(a-c_{0}\right) \underline{A}_{H}$, which consist of $\left(a-c_{0}\right) \underline{A}_{H}$ in access fees generated by the new customer, plus the same amount that the firm no longer needs to pay its rival in access fees.
} 
increases or decreases. It represents the effects of competition for heavy users. Further algebra (see Appendix B) gives an explicit expression for $\Delta p_{L}$ and hence $p_{L}$

$$
\Delta p_{L}=\frac{C_{1}\left(a-c_{0}\right)^{2}+C_{2}\left(a-c_{0}\right)+C_{3}}{C_{4}+C_{5}\left(a-c_{0}\right)}
$$

with the coefficients, which are independent of the access charge given below:

$$
\begin{aligned}
& C_{1}=-\frac{3 \bar{k} \gamma(1-\mu)}{4} \\
& C_{2}=b \mu-\left.4 \gamma \bar{k}(1-\mu) \underline{A}_{H}\left(\bar{q}_{L}^{0}, q_{H}\right)\right|_{a=c_{0}} \\
& C_{3}=-4 \gamma \bar{k} b(1-\mu)\left[t_{H}-c q_{H}-f\right]_{a=c_{0}} \\
& C_{4}=2 b \mu+2 \gamma \bar{k}^{2}(1-\mu) \\
& C_{5}=-2 \mu \gamma \bar{k}(1-l) .
\end{aligned}
$$

Clearly, $C_{4}$ is positive, and both $C_{1}$ and $C_{5}$ are negative. The lemma below establishes that $C_{3}<0$.

Lemma 1 The coefficient $C_{3}$ is negative.

Proof. $C_{3}=-4 \gamma \bar{k} b(1-\mu)\left[t_{H}-c q_{H}-f\right]_{a=c_{0}}$ which is equal to a term which is negative multiplied by the equilibrium profit per heavy user for $a=c_{0}$. Suppose the firm offered only the suboptimal package $\left(t_{L}, q_{L}\right)$ to both heavy and light users. Since the incentive constraint is binding, the consumer surplus for heavy users is unchanged and there would be no incentive to switch firms. Clearly, profits for this tariff package must be less than or equal to profits generated by the profit maximizing package. Thus

$$
\begin{aligned}
& \left.\frac{(1-\mu)}{2}\left(t_{H}-c q_{H}-f\right)\right|_{a=c_{0}}+\left.\frac{\mu}{2}\left(t_{L}-c q_{L}-f\right)\right|_{a=c_{0}} \geq\left.\left(t_{L}-c q_{L}-f\right)\right|_{a=c_{0}} \\
\Longleftrightarrow & \left.\left(t_{H}-c q_{H}-f\right)\right|_{a=c_{0}} \geq\left.\left(t_{L}-c q_{L}-f\right)\right|_{a=c_{0}}
\end{aligned}
$$

which proves the result since total profit must be positive.

When both constraints are binding, the tariffs can be found in terms of $q_{L}$ and $q_{H}$ from the constraint equations. The usage fees can be derived from the constraints which are binding together with equations (12), (27) and (29). The full tariff menu is:

$$
\begin{aligned}
& t_{L}=V_{L}\left(q_{L}\right), \quad t_{H}=V_{H}\left(q_{H}\right)-\bar{k} q_{L} \\
& p_{L}=c+\frac{(1-\mu)}{\mu} \bar{k}+\Delta p_{L}, \quad p_{H}=c+\frac{a-c_{0}}{2} .
\end{aligned}
$$




\subsubsection{The profit maximizing access charge}

Recall the intuition behind the results of Laffont et al. (1998) — increasing the access charge means that extra customers are more attractive, so firms cut the fixed fee to increase market share. The result is that the extra profits generated via high access charges are competed away in lower fixed fees. In contrast, here, if the participation and incentive constraint are both binding, competition for market share is no longer independent of the usage fee. In fact, for the light users the participation constraint means that their tariff is completely determined by the usage fee. An increase in the usage fee for the low demand customers means that the available consumer surplus is less and hence their overall tariff decreases. The incentive constraint forces firms to offer high demand customers more consumer surplus than the firms would wish to under perfect price discrimination. Hence, an increase in the usage fee for light users means that their package is less attractive for high demand users (who value call minutes more than light users) which means that firms can push up the tariffs for the heavy users. Thus, there is a direct link between the usage fee for light users and tariffs for both light and heavy users. The aim of the firms is to exploit the link between the usage fee for light users and the tariffs offered to each sector by using the access charge agreement to create incentives to move the equilibrium usage fees and tariffs in a competitive market as close as possible to that offered by the monopoly firm.

We are now in a position to see how changes in the access charging arrangement will affect profits. Since the equilibrium net access loss (or surplus) for each network is zero, the equilibrium profit is:

$$
\pi=\frac{\mu}{2}\left[V_{L}\left(q_{L}\right)-c q_{L}-f\right]+\frac{(1-\mu)}{2}\left[V_{H}\left(q_{H}\right)-c q_{H}-\bar{k} q_{L}-f\right]
$$

This can be written as a function of the access charge, using equations (3) and (30) as

$$
\pi\left(a-c_{0}\right)=\pi^{M}-\frac{\mu\left(\Delta p_{L}\right)^{2}}{8 b}-\frac{(1-\mu)\left(a-c_{0}\right)^{2}}{32 b},
$$

where $\pi^{M}$ is the monopoly profit at $\gamma=0$ and has no functional dependence on $a$. Note that for $\gamma=0, \Delta p_{L}=\left(a-c_{0}\right) / 2$ and the profit maximizing access charge is at $a=c_{0}$. If $a=c_{0}$, the derivative of the firms equilibrium profit with respect to access charge is

$$
\left.\frac{d \pi}{d a}\right|_{a=c_{0}}=-\left.\frac{\mu \Delta p_{L}}{4 b} \frac{d \Delta p_{L}}{d a}\right|_{a=c_{0}} .
$$

If $\gamma>0$, then the lemma shows that $\left.\Delta p_{L}\right|_{a=c_{0}}<0$. Hence, at $a=c_{0}$, the derivative of the profit function has the same sign as the sign of $d \Delta p_{L} / d a$. 
Differentiating equation (29) gives

$$
\left.\frac{d p_{L}}{d a}\right|_{a=c_{0}}=\left.\frac{d \Delta p_{L}}{d a}\right|_{a=c_{0}}=\frac{\left(C_{4} C_{2}-C_{5} C_{3}\right)}{C_{4}^{2}} .
$$

Thus, the profit will initially increase as the access charge increases if $\left(C_{4} C_{2}-\right.$ $\left.C_{5} C_{3}\right)>0$. The following proposition generalizes this to show that the profit maximizing access charge is positive or negative depending on the sign of this derivative at $a=c_{0}$.

Proposition 2 If $\gamma>0$, the profit maximizing optimum access charge is above cost (below cost) if $C_{4} C_{2}-C_{5} C_{3}>(<) 0$.

Proof. Write $\pi=\pi\left(a-c_{0}\right)$ and $\Delta p_{L}=\Delta p_{L}\left(a-c_{0}\right)$ to denote explicitly their dependence on the access charge. Consider $\pi(x)-\pi(-x)$ with $x>0$. Using equation (31), it follows that

$$
\begin{aligned}
\pi(x)-\pi(-x) & =-\frac{\mu}{8 b}\left(\left(\Delta p_{L}(x)\right)^{2}-\left(\Delta p_{L}(-x)\right)^{2}\right) \\
& =-\frac{\mu}{8 b}\left(\Delta p_{L}(x)+\Delta p_{L}(-x)\right)\left(\Delta p_{L}(x)-\Delta p_{L}(-x)\right) .
\end{aligned}
$$

For $x=0$ and $\gamma>0, \Delta p_{L}<0$. Clearly, the maximum profit must be at a value of $a$ where $\Delta p_{L}\left(a-c_{0}\right) \leq 0$ since if $\Delta p_{L}\left(\bar{a}-c_{0}\right)=0$, equation (31) reduces to $\pi\left(\bar{a}-c_{0}\right)=\pi^{M}-(1-\mu)\left(\bar{a}-c_{0}\right)^{2} / 32 b$. Inspecting equation (31), it is clear that if $\left|a-c_{0}\right|>\left|\bar{a}-c_{0}\right|, \pi\left(a-c_{0}\right)<\pi\left(\bar{a}-c_{0}\right)$. This shows that the maximum profit must be a value of $a$ with $a \in\left[-\left(\bar{a}-c_{0}\right), \bar{a}-c_{0}\right]$.

We will show that for $\Delta p_{L}(x)<0, \pi(x)-\pi(-x)>(<) 0$ for $C_{4} C_{2}-C_{5} C_{3}>(<$ )0. Thus, the optimum access charge will be above cost if $C_{4} C_{2}-C_{5} C_{3}$ is positive and will be below cost if $C_{4} C_{2}-C_{5} C_{3}$ is negative. Since $\Delta p_{L}(x)+\Delta p_{L}(-x)$ is negative, equation (34) shows that $\pi(x)-\pi(-x)$ is equal to a positive number multiplied by $\left(\Delta p_{L}(x)-\Delta p_{L}(-x)\right)$. Thus, the optimum access charge will be above cost if for all $x \in\left[0, \bar{a}-c_{0}\right],\left(\Delta p_{L}(x)-\Delta p_{L}(-x)\right)>0$ and below cost if $\left(\Delta p_{L}(x)-\Delta p_{L}(-x)\right)<0$. From equation (29), it follows that

$$
\begin{aligned}
& \Delta p_{L}(x)-\Delta p_{L}(-x)= \\
& \frac{C_{1} x^{2}+C_{2} x+C_{3}}{C_{4}+C_{5} x}-\frac{C_{1} x^{2}-C_{2} x+C_{3}}{C_{4}-C_{5} x}=\frac{2\left(C_{4} C_{2} x-C_{5} C_{3} x-C_{5} C_{1} x^{3}\right)}{C_{4}^{2}-C_{5}^{2} x^{2}} .
\end{aligned}
$$

Since $q_{L}$ is finite and positive, it must be the case that $C_{4}+C_{5} x>0$, so that $C_{4}^{2}-C_{5}^{2} x^{2}>0$, and it is sufficient to examine

$$
C_{4} C_{2}-C_{5} C_{3}-C_{5} C_{1} x^{2} .
$$


If $C_{4} C_{2}-C_{5} C_{3}<0$, this expression is always negative for all values of $x$, and the optimum access charge must be less than cost.

If $C_{4} C_{2}-C_{5} C_{3}>0$, the expression is positive only for all $x<\underline{x}$, where $\underline{x}$ is defined by $C_{4} C_{2}-C_{5} C_{3}=C_{5} C_{1} \underline{x}^{2}$. Note that $\Delta p_{L}(\underline{x})=\Delta p_{L}(-\underline{x})$. We claim that the profit maximizing value of $x$ is in the region defined by $x<\underline{x}$. This will follow if we can show that for all $x>\underline{x},\left|\Delta p_{L}(x)\right|>\left|\Delta p_{L}(\underline{x})\right|$ and $\left|\Delta p_{L}(-x)\right|>\left|\Delta p_{L}(-\underline{x})\right|$. Equation (34) shows that if this is the case, the maximum profit has to be at a value of $a-c_{0} \in(-\underline{x}, \underline{x})$. Now,

$$
\left|\Delta p_{L}(x)\right|-\left|\Delta p_{L}(\underline{x})\right|=-\frac{C_{1} x^{2}+C_{2} x+C_{3}}{C_{4}+C_{5} x}+\frac{C_{1} \underline{x}^{2}+C_{2} \underline{x}+C_{3}}{C_{4}+C_{5} \underline{x}} .
$$

Using $C_{4} C_{2}-C_{5} C_{3}=C_{5} C_{1} \underline{x}^{2}$, the expression reduces to

$$
\left|\Delta p_{L}(x)\right|-\left|\Delta p_{L}(\underline{x})\right|=\frac{-(x-\underline{x}) C_{1}(x+\underline{x})}{C_{4}+C_{5} x}>0,
$$

since $C_{1}<0$ and $x>\underline{x}$. Similarly, $\left|\Delta p_{L}(-x)\right|>\left|\Delta p_{L}(-\underline{x})\right|$ for $x>\underline{x}$.

Since $\left|\Delta p_{L}(-\underline{x})\right|=\left|\Delta p_{L}(\underline{x})\right|$, this shows that the access charge that maximizes profit satisfies $a-c_{0} \in[-\underline{x}, \underline{x}]$. By construction, if $x \in(0, \underline{x})$ then $C_{4} C_{2}-$ $C_{5} C_{3}-C_{5} C_{1} x^{2}>0$. Hence, if $C_{4} C_{2}-C_{5} C_{3}>0$, then $\pi(x)>\pi(-x)$ in this region and the optimum access charge is above cost.

Inspection of equation (31) and the proposition show that for $\gamma>0$, equilibrium profits will be maximized by increasing the price for the light users. To understand how firms use the access charge to boost profits, it is necessary to understand how competition impacts on the firms' equilibrium profits. If firms can set the access charge to counter the impact of increased competition, they will increase their profits. Suppose that $a=c_{0}$. Inspection of equation (28) and (30) show that

$$
\Delta t_{H}=-\gamma \frac{\bar{k}^{2}(1-\mu)}{b \mu}\left[t_{H}-c q_{H}-f\right]_{a=c_{0}} .
$$

Hence, greater competition causes firms to cut the "fixed part" of the tariffs offered to high demand users in an attempt to gain extra market share by offering them more consumer surplus. Light users continue to receive no consumer surplus as long as the participation constraint is binding. In fact, because heavy users are offered a more attractive package, the incentive constraint is relaxed somewhat and light users are offered a lower usage fee. As long as the participation constraint is binding, the lower usage fee for light users means their tariff will be higher.

Ideally, the firms would like to set the access charge so that the equilibrium usage fee for light users is increased to the monopoly value whilst leaving the 
equilibrium usage fee for heavy users at cost. The incentive and participation constraints then fix the tariffs to their monopoly rates. ${ }^{14}$

For small $\gamma$ and keeping terms linear in $\gamma$ and $a-c_{0}$ only, increasing the access charge above cost increases $p_{L}$ by $\left(a-c_{0}\right) / 2$. Thus, choosing an above cost access charge results in an increase in the equilibrium value of $p_{L}$ via the raise each other's cost effect and profits can be increased. Unfortunately, from the firms' point of view, the increase in the access charge means that the equilibrium value of $p_{H}$ is increased for exactly the same reason. Thus, there is a trade-off and although profits can be increased, monopoly profits cannot be restored. The profit maximizing access charge will be above $c_{0}$, resulting in $p_{L}$ being lower than desired and $p_{H}$ being higher than desired. Differentiating equation (31) with respect to $\left(a-c_{0}\right)$, keeping terms up to quadratic order in $\gamma$ and $\left(a-c_{0}\right)$, and setting to zero after substitution of equation (29), the profit maximizing access charge is

$$
\left(a-c_{0}\right)=4 \gamma \bar{k}(1-\mu)\left[t_{H}-c q_{H}-f\right]_{a=c_{0}} .
$$

It is easily checked that the profit maximizing access charge results in a usage fee for light users which has increased but is still below the monopoly usage fee.

For higher values of $\gamma$, the approximate change in the equilibrium usage fee $p_{L}$ for small $a-c_{0}$ needs to include terms which are quadratic order in $\gamma$ and $\left(a-c_{0}\right)$. It is equal to

$$
p_{L}=p_{L}^{0}+\left(1+2 \gamma \bar{k}^{2} \frac{(1-\mu)}{2 b \mu}\right)^{-1}\left[\frac{1}{2}-\left.\frac{2 \gamma \bar{k}(1-\mu)}{b \mu} \underline{A}_{H}\left(\bar{q}_{L}^{0}, q_{H}\right)\right|_{a=c_{0}}\right]\left(a-c_{0}\right)
$$

where $p_{L}^{0}$ is the usage fee at $a=c_{0}$. The proposition shows that for this approximate solution, the profit maximizing access charge is greater than cost as long as the term in square brackets is positive. There is now a new factor which becomes important in determining the profit maximizing access charge - the call imbalance effect. Changing the access charge has a direct impact on the access revenue collected from heavy users. By a judicious choice of reciprocal access charges, firms can limit competition for heavy users by ensuring that they bring with them negative access revenue, which translates into a higher usage fee for light users via the incentive and participation constraints. If there is a net outflow of calls from the heavy users sector, the raise each other's costs effect and the call imbalance effect both operate in the same direction giving an optimum $a>c_{0}$. If there is a net inflow of calls into the heavy users sector, and if competition is fierce enough, it is possible that the

\footnotetext{
${ }^{14}$ If firms could set a different access fee for calls terminating on each market segment, then potentially, with the extra degree of freedom at their disposal, they may be able to fix both $p_{L}$ and $p_{H}$ independently, thereby restoring monopoly profits.
} 
call imbalance effect will outweigh the raise each other's cost effect leading to an optimal access charge which is below cost.

The above discussion can be summarized - firms can increase profits by agreeing on access charges that differ from costs, their profits will still be less than monopoly profits, and under light competition between firms the profit maximizing access charge is above cost. As competition increases, the profit maximizing access charge usually remains above cost. However, with significant competition and a large net inflow of calls into the heavy users sector, the profit maximizing access charge may become below cost.

For higher levels of competition, it is likely that the firms will attempt to increase market share for light users as well, which means offering them some consumer surplus, so that the participation constraint may cease to be binding. For heavy users, increased competition means the firms may offer a tariff package which leaves them with more consumer surplus than is required by the incentive constraint. Thus, to understand profit maximizing access arrangements for higher levels of competition, we need to be able to check if the constraints are binding. Indeed, it turns out that changing the access charge can result in the solution moving between different regions of the solution space. For example, one choice of the access charge could result in both constraints being binding, while a different choice could result in only the participation constraint being binding. To proceed further, we need to look at numerical solutions to help understand the interplay between competition, access charges and the binding constraints. Before doing so, we briefly note how these profit maximizing access charges compare to those which are socially optimal.

\subsubsection{Socially optimum access charge}

We have seen above that firms can set an access charge to partially counter the impact of competition on their profits. This suggests that the access charge can also be used by a regulator to have the reverse effect, possibly raising social welfare. Given our model of firm competition (see Appendix A), social welfare is just the sum of the firms' profits and consumer surplus (there are no transportation cost terms). Since the light users receive zero consumer surplus, it follows that

$$
\begin{aligned}
S W & =(1-\mu)\left[t_{H}-c q_{H}-f\right]+\mu\left[t_{L}-c q_{L}-f\right]+(1-\mu)\left[V_{H}\left(q_{H}\right)-t_{H}\right] \\
& =S W^{M}-\frac{(1-\mu)\left(a-c_{0}\right)^{2}}{16 b}-\frac{\mu\left[\Delta p_{L}+(1-\mu) \bar{k} / \mu\right]^{2}}{4 b}
\end{aligned}
$$


where $S W^{M}$ is the social surplus for $\gamma=0$ and $a=c_{0}$. The derivative of the social welfare function at $a=c_{0}$ is therefore

$$
\left.\frac{d S W}{d a}\right|_{a=c_{0}}=-\left.\frac{\mu}{2 b}\left[\Delta p_{L}+(1-\mu) \bar{k} / \mu\right] \frac{d \Delta p_{L}}{d a}\right|_{a=c_{0}} .
$$

Note that the term in the square brackets is positive. This follows since $\Delta p_{L}+$ $(1-\mu) \bar{k} / \mu=2 \lambda_{2} \bar{k} / \mu+\left(a-c_{0}\right) / 2$ given equations (15) and (30), and since $\lambda_{2}$ is defined to be positive when the incentive constraint is binding. Examining equation (33), it follows that a regulator can improve social welfare by setting an access charge below cost if $C_{4} C_{2}-C_{5} C_{3}>0$ and above cost if $C_{4} C_{2}-C_{5} C_{3}<$ 0 . Thus, if the firms wish to collude over access charges and set access charges above cost (which is always the case for small $\gamma$ ), then social welfare can be improved by mandating an access charge which is below cost. We are assuming here that the firms are making positive profits if the access charge is set at cost. If they are not, then the socially optimum access charge will allow the firms higher profits, and will be above cost if the profit maximizing access charge is above cost.

\section{Numerical solutions}

To illustrate the analytic arguments presented in the previous section, it is useful to specify parameter values and compute the solution presented in equation (30). The equations only apply if both the incentive and participation constraints are binding, which is true for small enough values of $\gamma$ (light competition). To map out the solution for other regions of the solution space, it is important to check that it is optimal for firms to keep both constraints binding or whether they are better off to relax one or both constraints. As long as the computed values of the associated Lagrange multipliers $\lambda_{1}$ and $\lambda_{2}$ are positive, both constraints will be binding. However, if the computed value of $\lambda_{i}$ $(i=1,2)$ is zero or negative, then the relevant constraint is no longer binding and a new solution needs to be found with only the remaining constraint binding. The solution with only the participation constraint binding is outlined in Section 3.2 (equations 19, 20, 21). With the incentive constraint of the heavy users no longer binding, the incentive constraint for the light users may not be satisfied, so we need to check this as well. ${ }^{15}$ If the participation constraint is not binding, the high demand customers no longer necessarily receive positive surplus from the light users package. Hence, the incentive constraint can be violated for either the high or the low demand users. This situation has been analyzed extensively by Dessein (1999a and 1999b) and the finding of direct

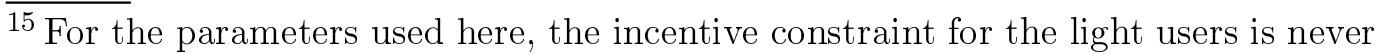
violated if the participation constraint is binding.
} 
relevance here is that the profit per firm is just $1 / 4 \gamma$ and is independent of the access charge (which is also the case if none of the constraints are binding). The strategy we use to compute the optimal profits is to map out the different regions of the solution space defined by

- Region I $\left(\lambda_{1}\right.$ and $\left.\lambda_{2}>0\right)$

- Region II $\left(\lambda_{1}>0\right.$ and $\left.\lambda_{2}=0\right)$

- Region III $\left(\lambda_{1}=0\right)$.

Profits will only depend on the access charge in regions I and II. The fact that there are different regions give firms a further plausible strategy for using the access charges to raise profits. By changing the negotiated access charge, it may be possible to move between the different regions of the solution space. Thus, as well as illustrating the general arguments and results derived in the previous two sections, the numerical computations can be used to analyze just such a scenario.

We will continue to specify linear demand. The parameter values we will choose are to set the $\operatorname{costs} c=1$ and $c_{0}=0$, and the demand parameter $b=1$. The scenario we have in mind is that the two sectors consist of a business sector (high demand) and a residential sector (low demand). A high value is chosen for $\mu$, namely $\mu=0.75$, so that most customers are residential customers. Business customers are chosen to receive substantially more utility than residential customers from calls with $k_{H}=10$ and $k_{L}=5$. The demand parameters for high and low demand customers are set with a reasonable spread which means that both types of users will continue to demand the service for usage fees several times as high as marginal cost. The parameter governing the net outflow of calls from the low users is $l$. The call imbalance effect is an important factor in the profit maximizing access charge arrangements, so we will look at two scenarios $(l=0.2$ and $l=0.8)$. Given the assumption that $c_{0}$ equals zero, the parameter $a$ can be reinterpreted as the difference between the true access charge and the marginal cost of terminating (or connecting) a call.

We analyze the solution space for different values of the competition parameter $\gamma$ and the access charge $a$. The base-line scenario is an access charge negotiated at marginal cost (which is $a=0$ ). The usage fee for the high demand users is just $p_{H}=1$ for all values of the competition parameter. The usage fee for the low customers is graphed in figure 1 as a function of $\gamma$, as are the tariffs for both types of users. In region I, where both constraints are binding, as competition increases firms respond by trying to attract heavy users by lowering their overall tariff (while the usage fee remains the same). The lower tariffs for light users mean that firms are not forced to keep the light user package as unattractive to heavy users. This implies lower usage fees and higher overall tariffs for light users. The light users are indifferent between their new package and their old one, receiving zero consumer surplus from both. Once the usage 


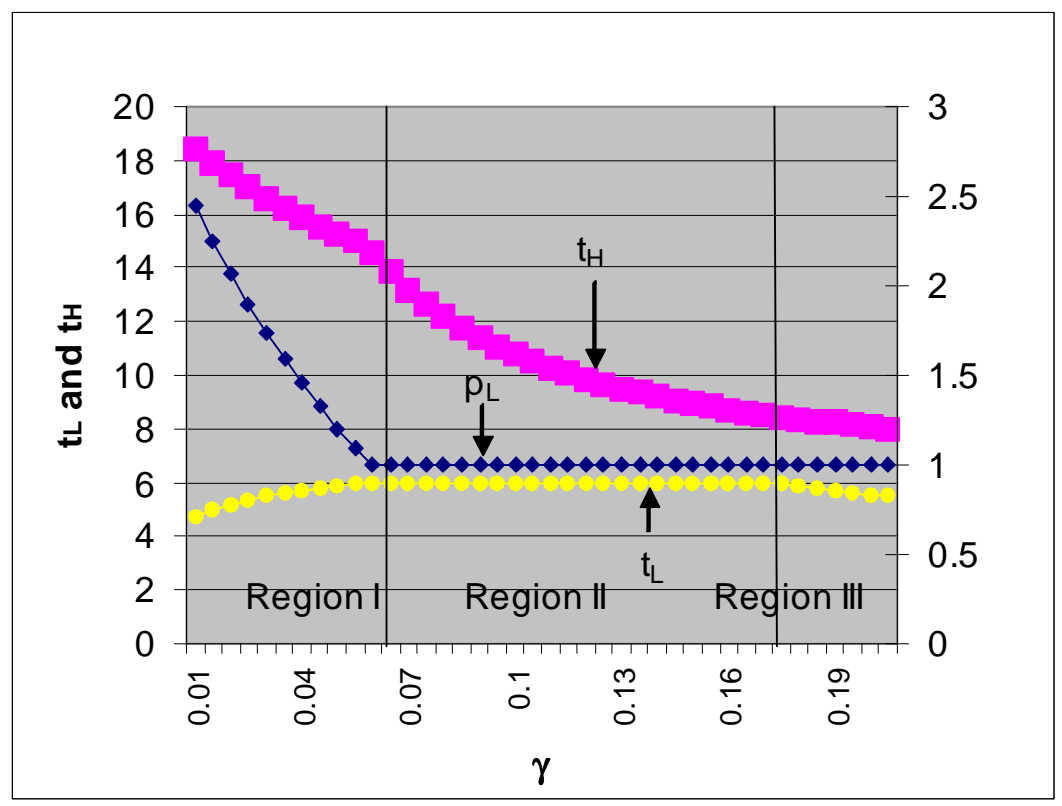

Fig. 1. Tarrifs and prices for $a=0$ as competition increases.

fee for light users is equal to marginal cost the incentive constraint ceases to be binding. In region II, the usage fee for the light users is fixed at marginal cost, so that the tariff for light users does not change. With the incentive constraint no longer binding, the two sectors operate independently. The usage fee for the heavy users remains at marginal cost. Firms, however, compete for heavy users by reducing the "fixed part" of their tariff. Finally, once competition is strong enough, firms start to compete for light users by reducing their "fixed fee" as well (region III). Total profits track steadily downwards in all three regions. However, in region I the increase in tariffs for the light users $(80 \%$ of the total market) partially compensates the firms for the loss of revenue from the heavy users, and the drop in profit with increased $\gamma$ is not as severe as in regions II and III.

As discussed in Section 3, for small values of $\gamma$ the firms can use the negotiated access charge to boost profits. Figure 2 illustrates the profit maximizing access charge for a light bias call imbalance $\left(\underline{A}_{H}<0\right)$ and a heavy bias call imbalance $\left(\underline{A}_{H}>0\right)$. For light competition, the optimum access charge is positive for both scenarios as the raise each other's cost effect dominates. However, for heavier competition the call imbalance effect becomes increasingly important, resulting in profit maximizing access charges which are positive for $\underline{A}_{H}<0$ and negative for $\underline{A}_{H}>0$. For example, if $\underline{A}_{H}>0$ there is an inflow of calls into the heavy users sector, so that access revenue is positive if $a$ is positive. When $\gamma$ is large enough, there is an incentive (if $a$ is positive) to cut tariffs for the heavy user segment to gain market share and extra access revenue, which would result in lower equilibrium profits. To prevent this, firms may wish to negotiate an access charge which is negative. For values of $\gamma \geq 0.11$, the 


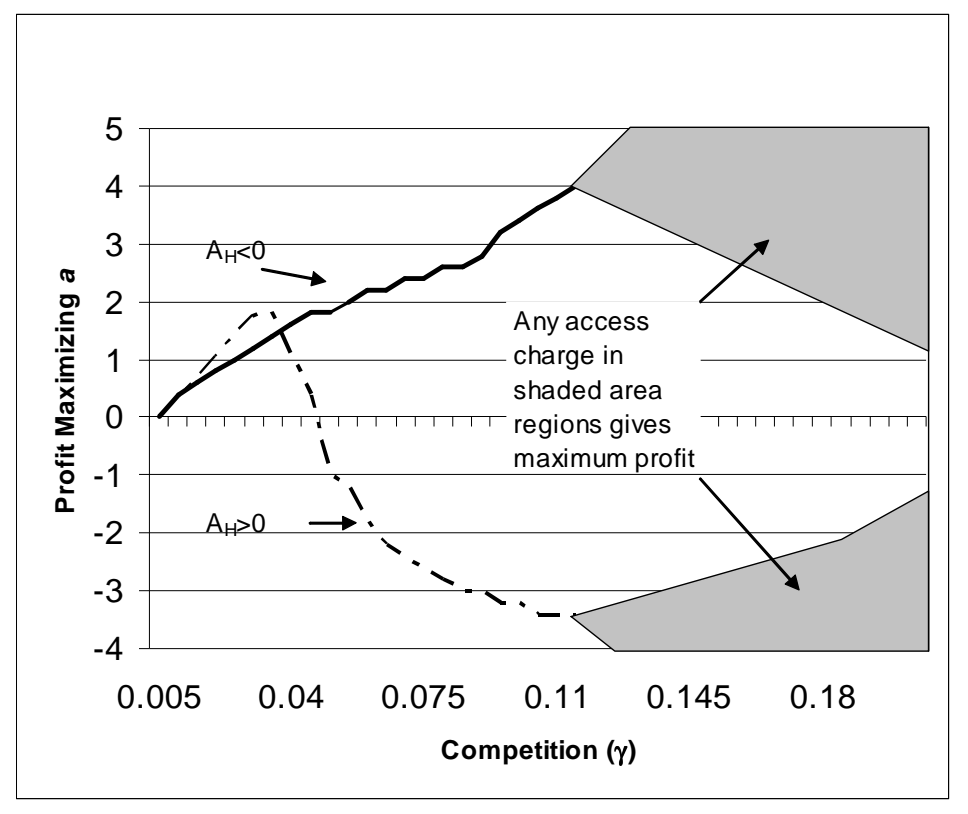

Fig. 2. Optimum access charge for light bias and heavy bias call imbalances

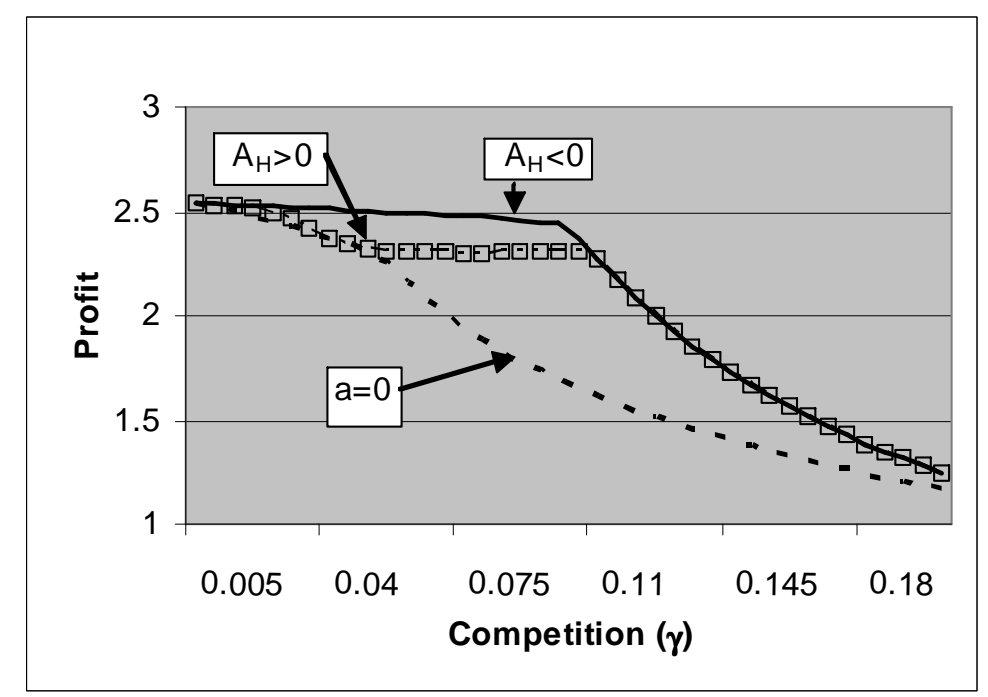

Fig. 3. Profits for optimum access charge compared to profits with access charge at cost

participation constraint ceases to be binding and the access charge neutrality result holds over a range of values. The outer limits of this range increase as $\gamma$ increases (as depicted in figure 2).

Figure 3 illustrates the increase in profits for firms if they negotiate an optimum access charge compared to profits obtained by firms for an access charge set equal to usage fee. The two top curves are the optimum profits for the light biased and heavy biased calling patterns. The value of the bias parameter $l$ has no effect on profits for $a=c_{0}$, so the equilibrium profit for access charge equal 


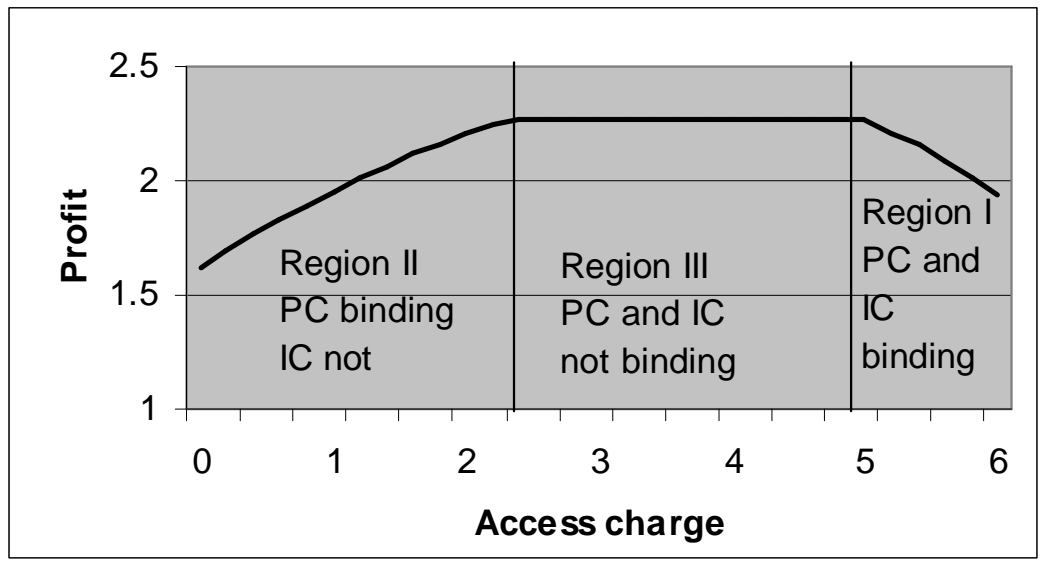

Fig. 4. Profit as a function of access charge for $\gamma=0.11$ and $\mu=0.8$

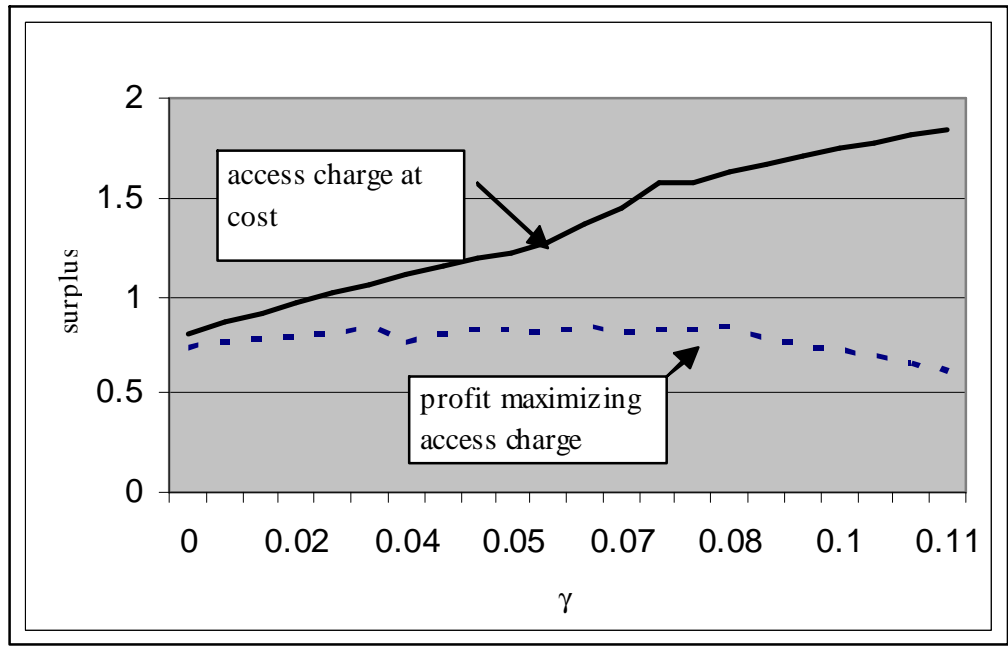

Fig. 5. Consumer surplus for $l=0.8$ : Optimal access charge vs. cost

to cost is the same for both scenarios. The incentive and participation constraints are binding for the $a=c_{0}$ curve for both scenarios up until $\gamma=0.055$ (region I). The incentive constraint ceases to be binding at this point, while the participation constraint remains binding. The increase in profits for the firms from negotiating the optimal access charge rather than setting access charges at cost can be significant - up to $40 \%$ in the two scenarios examined here.

It was noted at the beginning of the section that a plausible strategy for the firms to increase profits is by using the negotiated access charge to move between the different regions of solution space. Figure 4 illustrates the argument for $\gamma=0.11$ with $l=0.8$ (that is $\underline{A}_{H}>0$ ). At an access charge equal to cost (so $a=0$ ), the incentive constraint is non-binding. Increasing the access charge makes heavy users less attractive (since they start to incur a large access loss). As a result, $t_{H}$ increases and competition is deflected into the light users sector where it is initially ineffective. However, at high enough access 
charges the incentive to gain extra access revenue from light users is sufficiently strong and firms wish to offer light users a positive surplus. Hence, the participation constraint ceases to be binding (region III). This example illustrates quite dramatically the way firms can use the access charges to collude and reduce the loss of the profits forced on them by not being able to price discriminate perfectly. The final profit in region III is just the "Hotelling" profit which equals $1 / 4 \gamma$.

Finally, figure 5 illustrates that the increase in profits can be at a severe cost to consumer's surplus. For the scenario with a net outflow of calls from the high demand sector, the consumer surplus has been plotted. Compared to cost based access charges, allowing the firms to set their profit maximizing access charges results in quite large percentage falls in consumer surplus. In this example, the fall in consumer surplus can be as high as $70 \%$, which is a consequence of the firms using the access charge to increase their profit by $40 \%$. Total social surplus falls as well, although the effect is smaller - a $16 \%$ drop in this case.

\section{Conclusion}

We have seen that introducing an explicit participation constraint for light uses breaks the neutrality of access charge first introduced by Laffont et al. (1998) and extended to a model with heterogenous customers by Dessein (2003). If competition is not too fierce, we have seen that firms can use the raise each other's cost effect and the call imbalance effect to redirect competitive pressures from the heavy user sector to the light users sector, where it is ineffective. The result can be higher profits for the firms but lower consumer and total surplus. For low degrees of competition, the profit maximizing access charge is always above cost, while social welfare can be increased by mandating access charges below cost.

This suggests if facilities based competition is limited and retail prices are left unregulated, then there is still a need for reciprocal access charges to be regulated, even in a world in which firms are symmetric and can set non-linear prices.

The assumptions adopted here, that there are two types of users and that firms service both types of customers, should provide a reasonable approximation to fixed line networks with business and residential customers. However, it would certainly be useful to develop models of heterogenous users in which some consumers do not participate in the network at all. Existing models that address this question all assume away heterogeneity over demand for calls. As well as being essential to understanding the interaction between access 
charges and participation constraints in mobile networks, such a model would help extend and deepen the insights developed here for fixed-line networks. It would also be of interest to consider a model where firms could negotiate segment specific access charges. The intuition developed here suggests that it is likely that firms could use the additional instruments to collude and restore monopoly profits, at least for limited levels of competition.

\section{Acknowledgements}

We would like to thank a refereree for very helpful comments. We also gratefully acknowledge financial support from the Centre for Research in Network Economics and Communications at the University of Auckland.

\section{Appendix A Modified model of consumer choice}

We take as the starting point that half the consumers are informed of each firm (we are interested in a mature market setting, so it seems reasonable to start with the assumption that these shares are initially equal). Consumers find out about the other firm with a certain probability. This probability is assumed to depend on the utilities (packages) offered by the two firms. Firms that offer better packages will be noticed by more people, perhaps through word of mouth.

Specifically, suppose the utility offered by firm 1 is $w_{1}$ and the utility offered by firm 2 is $w_{2}$. Consumers want to maximize their utility, but they may not learn of the package offered by the second firm. Consider how many consumers will buy from each firm. No consumer will buy from a firm $i$ if $w_{i}<0$. Thus, if $w_{1}<0$ and $w_{2}<0$, then no consumers will purchase. Suppose $w_{i} \geq 0$ and $w_{j}<0$. In this case, we assume all consumers will be informed of the package on firm $i$, and all buy from firm $i$. Finally, consider what happens if $w_{1} \geq 0$ and $w_{2} \geq 0$. In this case, suppose the probability a consumer who currently knows of firm $j$ 's deal will hear of firm $i$ 's deal is linear in the difference in utilities. This probability must of course be bounded between 0 and 1 . We choose the following form for the probability, since it gives rise to the standard Hotelling share function

$$
\begin{aligned}
& 0 \text { if } w_{i} \leq w_{j} \\
& \frac{w_{i}-w_{j}}{\tau} \text { if } w_{j}<w_{i}<w_{j}+\tau \\
& 1 \text { if } w_{i} \geq w_{j}+\tau
\end{aligned}
$$

for $i, j=1,2$ and $i \neq j$. 
If $w_{i} \geq w_{j}$, then a fraction

$$
\frac{w_{i}-w_{j}}{\tau}
$$

of consumers who only know of firm $j$ 's deal will learn of firm $i$ 's better deal and buy from firm $i$. This gives firm $i$ a share

$$
\frac{1}{2}+\frac{w_{i}-w_{j}}{2 \tau}
$$

while firm $j$ is left with a share

$$
\frac{1}{2}+\frac{w_{j}-w_{i}}{2 \tau}
$$

of consumers. If $w_{j}>w_{i}$, then the symmetric argument applies to consumers on firm $j$.

In the paper, for notational convenience, the parameter $1 / 2 \tau$ is replaced by $\gamma$, so the market share of the representative firm is

$$
\alpha_{S}=\frac{1}{2}+\gamma\left(u_{S}\left(q_{S}, t_{S}\right)-u_{S}\left(q_{S}^{\prime}, t_{S}^{\prime}\right)\right) .
$$

Note, higher $\gamma$ will imply that the probability consumers learn of the other firm's package is more sensitive to the firm offering a better deal. The result is to make firms more competitive. Moreover, the participation constraint for the representative firm is

$$
u_{L}=V_{L}\left(q_{L}\right)-t_{L} \geq 0
$$

Appendix B Exact expressions for usage fee for light users when both constraints are binding Using equation (11) to substitute for $\lambda_{2}$ into equation (10) gives

$$
\begin{aligned}
& (1-\mu) \gamma\left[t_{H}-c q_{H}-f\right]+2(1-\mu) \gamma\left(a-c_{0}\right) \underline{A}_{H} \\
= & \frac{\mu}{2}\left[V_{L}^{\prime}\left(q_{L}\right)-\left(c+\frac{\left(a-c_{0}\right)}{2}\right)\right]\left[V_{L}^{\prime}\left(q_{L}\right)-V_{H}^{\prime}\left(q_{L}\right)\right]^{-1}+(1-\mu) / 2 .
\end{aligned}
$$

Since $q_{H}$ is determined from (12) and the incentive constraint equation tells us what $t_{H}$ is in terms of $q_{L}$ and $q_{H}$, equation (42) can be solved for $q_{L}$. Inserting the gross surplus functions

$$
V_{S}\left(q_{S}\right)=\left(k_{S}-b q_{S}\right) q_{S}
$$


into equation (42) and rearranging we can solve for $q_{L}$ to find that

$$
q_{L}=\frac{2 \gamma \bar{k}(1-\mu)\left[V_{H}-c q_{H}-f\right]-2 \gamma \bar{k}\left(a-c_{0}\right) l(1-\mu) q_{H}+2 b \mu q_{L}^{0}}{2 b \mu+2 \gamma(1-\mu) \bar{k}^{2}-2 \gamma \bar{k}\left(a-c_{0}\right) \mu(1-l)},
$$

where the value of $q_{L}$ for $\gamma=0$ is denoted $q_{L}^{0}$ and is given by

$$
q_{L}^{0}=\frac{k_{L}-c-\left(a-c_{0}\right) / 2-\bar{k}(1-\mu) / \mu}{2 b} .
$$

Inserting equation (44) into equation (28) gives

$$
p_{L}=c+\frac{(1-\mu)}{\mu} \bar{k}+\Delta p_{L},
$$

where $\Delta p_{L}$ is a function of $\left(a-c_{0}\right)$ and is given by

$$
\Delta p_{L}=\frac{\left(a-c_{0}\right)}{2}-\frac{2 \gamma(1-\mu) \bar{k} b}{\left[b \mu+\bar{k}^{2}(1-\mu)-\mu \bar{k}(1-l)\left(a-c_{0}\right)\right]} R_{H}\left(q_{H}, q_{L}^{0}\right) .
$$

Inserting equation (45) and (12) into equation (47) and collecting powers of $\left(a-c_{0}\right)$, reveals after some algebra that

$$
\Delta p_{L}=\frac{C_{1}\left(a-c_{0}\right)^{2}+C_{2}\left(a-c_{0}\right)+C_{3}}{C_{4}+C_{5}\left(a-c_{0}\right)},
$$

with the coefficients which are independent of the access charge given in Section 3.3. The usage fee that a monopoly $(\gamma=0)$ would offer light users if the access fees were set at cost is denoted by $\bar{q}_{L}^{0}$.

\section{References}

Armstrong, M., 1998, Network Interconnection, The Economic Journal 108: 545564

Armstrong, M., 2002, The Theory of Access Pricing and Interconnection, in: Martin Cave, Sumit Majumdar and Ingo Vogelsang, eds., Handbook of Telecommunications Economics, Volume 1(North-Holland, Amsterdam).

Carter, M. and J. Wright, 1999, Interconnection in Network Industries, Review of Industrial Organization 14: 1-25

Carter, M. and J. Wright, 2003, Asymmetric Network Interconnection, Review of Industrial Organization 22: 27-46

De Bijl, P. and M. Peitz, 2002, Regulation and Entry into Telecommunications Markets, (Cambridge University Press, Cambridge)

Dessein, W.,1999a, Network Competition in Nonlinear Pricing., mimeu, Ecares, ULB.

Dessein, W.,1999b, Network Competition with Heterogeneous Calling Patterns, mimeu, Ecares, ULB 
Dessein, W., 2003, Network Competition in Nonlinear Pricing, Rand Journal of Economics, forthcoming.

Gans, J. and S. King, 2001, Using 'Bill and Keep' Interconnect Agreements to Soften Network Competition, Economics Letters 71: 413-420

Hahn, J-H., 2000, Network Competition and Interconnection with Heterogeneous Subscribers, Keele Economics Research Paper 2000-11

Laffont J. and J. Tirole, 1999, Competition in Telecommunications (MIT Press).

Laffont J., P. Rey and J. Tirole,1998, Network Competition : I Overview and Nondiscriminatory Pricing, Rand Journal of Economics 29: 1-37

Schiff, A., 2002, Two-Way Interconnection with Partial Consumer Participation, Networks and Spatial Economics 2: 295 - 315

Tirole J., 1988, Industrial Organization (MIT Press).

Valletti, T.M. and C. Cambini 2002, Investments and network competition, mimeo, Imperial College London.

Wright, J., 2002, Access Pricing under Competition: An Application to Cellular Networks, Journal of Industrial Economics 50: 289 - 315 